\title{
Current status of bevacizumab in advanced ovarian cancer
}

This article was published in the following Dove Press journal:

OncoTargets and Therapy

19 July 2013

Number of times this article has been viewed

\section{Federica Tomaol,* \\ Anselmo $\mathrm{Papa}^{2, *}$ \\ Luigi Rossi ${ }^{2}$ \\ Davide Caruso ${ }^{2}$ \\ Pierluigi Benedetti Panici' \\ Martina Venezia ${ }^{2}$ \\ Silverio Tomao ${ }^{2}$ \\ 'Department of Gynaecology and Obstetrics, "Sapienza" University of Rome, Policlinico "Umberto I," Rome, Italy; 'Department of Medico- Surgical Sciences and Biotechnologies, "Sapienza" University of Rome, Oncology Unit, "ICOT," Latina, Italy \\ *Authors contributed equally to this work}

Correspondence: Anselmo Papa

Piazza Giacinto Carbone,

37 Pontecorvo 03037, Italy

Tel +39320 2231228

Email anselmo.papa@libero.it
Abstract: Ovarian cancer is the most lethal gynecological cancer, mainly because of the delay in diagnosis. Recently, much effort has been put into investigating and introducing novel targeted agents into clinical practice, with the aim of improving prognosis and quality of life. Angiogenesis is a possible target. The aim of this review is to investigate the most common molecular pathways of angiogenesis, which have provided novel targets for tailored therapy in patients with ovarian cancer. These therapeutic strategies include monoclonal antibodies and tyrosine-kinase inhibitors. These drugs have as molecular targets vascular endothelial growth factor, vascular endothelial growth factor receptors, platelet-derived growth factor, fibroblast growth factor, and angiopoietin. Bevacizumab was investigated in several Phase III studies, with interesting results. Today, there is strong evidence for introducing bevacizumab in the treatment of patients with advanced and recurrent ovarian cancer. Nevertheless, further investigations and large clinical trials are needed to understand the safety and effectiveness of bevacizumab, the optimal duration and timing of treatment, and activity in association with other chemotherapeutic and targeted agents. It also is necessary to identify biologic factors predictive of efficacy to choose the most appropriate antiangiogenic agent in the integrated treatment of epithelial ovarian cancer.

Keywords: epithelial ovarian cancer, angiogenesis, bevacizumab, vascular endothelial growth factor, chemotherapy

\section{Introduction}

Epithelial ovarian cancer (EOC) is the fourth most frequent cause of cancer death in European women and the most deadly gynecological tumor in Western countries, with unfavorable effects from an economic and social point of view. ${ }^{1}$ In 2010 , there were about 21,880 new cases of EOC and 13,850 deaths reported in the United States, and unlike other gynecologic cancers, for which the risk factors are well-known, the etiology of EOC is still unknown. ${ }^{1}$

The incidence of EOC increases with age and is most prevalent in the eighth decade of life, with a rate of $57 / 100,000$ women. ${ }^{2}$ The median age at the time of diagnosis is 63 years, and more than $70 \%$ of patients present with advanced disease. ${ }^{2}$

Unfortunately, there are no validated screening tests for this cancer, and most women present with advanced disease, reporting vague and confounding symptoms. Although the 5 -year survival rate is higher than $90 \%$ for women with early-stage EOC, about $80 \%$ of women present with late-stage disease and have a 5 -year survival rate of only $30 \%{ }^{3}$

EOC typically spreads by local and regional diffusion, seeding of the peritoneal cavity and invasion through the lymphatic vessels. Because of this long and characteristic diffusion, radical surgery plays an important role in the diagnosis, 
staging, primary therapy, and treatment of recurrent disease. ${ }^{3}$ Standard therapy includes cytoreductive surgery preceded or followed by platinum/taxane combination chemotherapy (Figure 1). ${ }^{4}$ The most important drug in EOC is platinum, which showed an important increase in progression-free survival (PFS) and overall survival (OS) in patients affected by this disease. According to the response to therapy, EOC can be divided into: platinum-refractory, if there is a progression within 1 month or stable disease during first-line therapy; platinum-resistant, if there is a response during therapy and a relapse within 6 months; and platinum-sensitive if there is a relapse after 12 months post-therapy. ${ }^{5}$ The longer the interval from the end of platinum-based chemotherapy, the better the outcome; and the outcome is also better when using platinum. Patients with EOC who relapse within 6 to 12 months show an intermediate sensitivity to platinum; for this reason, they are called platinum-partially sensitive. $^{6}$

The response rate (RR) to chemotherapy is high, and sometimes impressive, with frequent evidence of clinical and pathological response, but unfortunately, 75\% of patients who initially respond to conventional chemo-

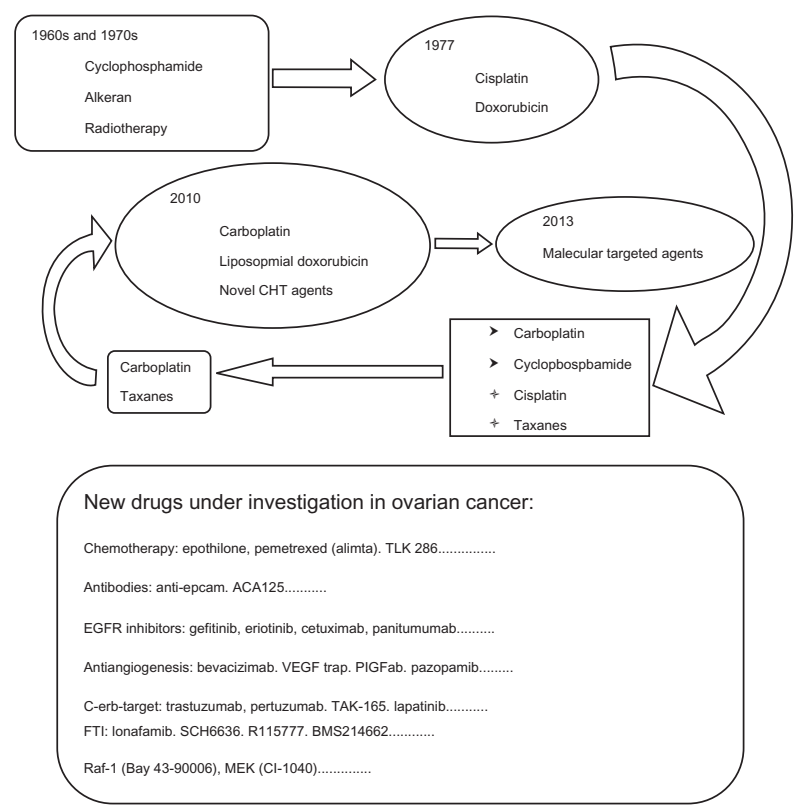

Figure I Evolution of medical therapy in ovarian cancer with new drugs under investigation.

Abbreviations: EGFR, epidermal growth factor receptor; VEGF, vascular endothelial growth factor; MEK, mitogen-activated protein kinase kinase; PIGFab, phosphatidylinositol-glycan biosynthesis class F; FTI, farnesyl transferase inhibitor; $\mathrm{CHT}$, chemotherapy; TLK286, glutathione S-transferase PI-I activated glutathione analogue; ACA 25 , murine anti-idiotypic antibody of the tumor-associated antigen CA-I 25; TAK I 65, I-(4-\{4-[(2-\{(E)-2-[4-(trifluoromethyl)phenyl]ethenyl\}-I,3-oxazol4-yl)methoxy]phenyl\}butyl)-I H-I,2,3-triazole; SCH6636, farnesyl protein transferase inhibitor; BMS2 14662, farnesyltransferase inhibitor. therapy have a fatal relapse. Recurrent EOC constitutes a disease with a very poor prognosis, forcing patients to receive multiple lines of chemotherapy with unsatisfactory results, in terms of RR, PFS, and OS, because of the occurrence of drug-resistant cancer clones. For these reasons and also to identify more appropriate therapeutic options, a considerable scientific interest has developed in the identification of new molecular targets and alternative molecular pathways involved in ovarian carcinogenesis; moreover, a large number of novel molecular targeted agents and innovative therapeutic associations of chemotherapy are currently under investigation for the treatment of EOC (Table 1). ${ }^{6}$

\section{Role of angiogenesis in EOC}

Angiogenesis is a characteristic biological phenomenon by which new blood vessels are generated to develop neovascularization, supporting cellular growth and modifications in the target tissues. Angiogenesis is an important mechanism of differentiation in humans and it is also involved in normal proliferative processes such as pregnancy, embryogenesis, wound healing, and the female reproductive cycle. Moreover, in 1971, Folkman proposed that angiogenesis and neovascularization are able to facilitate the tumor growth and the metastatic process, allowing malignant cells to spread in the circulatory system. ${ }^{7,8}$

Angiogenesis is a multistep process driven by tumorgenerated growth factors that operate along several convergent and divergent pathways, consisting of an initiation phase and a maturation phase. The initiation phase is activated by tumor-derived cytokines (as vascular endothelial growth factor [VEGF]) and is characterized by the production and occurrence of permeable microvascular networks deriving from existing blood and lymphatic vessels. In the successive maturation phase, these morphological changes become functional by a biological point of view, favoring the activation of tumor proliferation, invasion and metastasis. ${ }^{9}$

Moreover, increased angiogenesis, as manifested by increased tumor microvessel density (MVD), has been associated with a decreased delivery of chemotherapeutic agents and worse clinical outcome in a variety of solid tumors, including EOC. ${ }^{10,11}$

Overall, the published data indicate that a high degree of tumor angiogenesis is predictive of poor clinical outcome, with three studies reporting that higher MVD is an independent prognostic factor for improved survival in women with advanced EOC. ${ }^{12-15}$ 
Table I Prospective clinical trials of novel cytotoxic agents in EOC

\begin{tabular}{|c|c|c|c|c|c|c|c|}
\hline Study & Agent & Phase & Patients & $\begin{array}{l}\text { Platinum } \\
\text { sensitive (\%) }\end{array}$ & $\begin{array}{l}\text { Response } \\
\text { rate (\%) }\end{array}$ & $\begin{array}{l}\text { Stable } \\
\text { disease (\%) }\end{array}$ & $\begin{array}{l}\text { mPFS } \\
\text { (months) }\end{array}$ \\
\hline Sessa et $\mathrm{al}^{77}$ & TR & II & 59,51 evaluable & 49 & $\begin{array}{l}\text { Sensitive: } 43 \text {; } \\
\text { resistant: } 7\end{array}$ & $\begin{array}{l}\text { Sensitive: } 39 \text {; } \\
\text { resistant: } 33\end{array}$ & na \\
\hline Krasner et a ${ }^{78}$ & TR & ॥ & $|47| 4 \mid$, evaluable & 45 & $\begin{array}{l}\text { Sensitive: } 29 \text {; } \\
\text { resistant: } 6.3\end{array}$ & $\begin{array}{l}\text { Sensitive: } 35 \text {; } \\
\text { resistant: } 46\end{array}$ & $\begin{array}{l}\text { Sensitive: } 5.1 \text {; } \\
\text { resistant: } 2\end{array}$ \\
\hline \multirow[t]{2}{*}{ Del Campo et al ${ }^{79}$} & TR & ॥ & I07, 99 evaluable & 100 & A: 29 & A: 52 & na \\
\hline & (2 doses: $A / B)$ & & & & B: 28 & B: 45 & \\
\hline \multirow[t]{2}{*}{ Monk et a ${ }^{80}$} & $\mathrm{TR}+\mathrm{PLD}$ & III & 672 & 64 & 27.6 & 7.3 & 7.3 \\
\hline & LPD & & & & 18.8 & 5.8 & 5.8 \\
\hline Smit et $\mathrm{al}^{81}$ & PAT & II & 112 & 0 & 6.3 & 44.6 & 2.8 \\
\hline Forster et al ${ }^{82}$ & $\mathrm{PAT}+\mathrm{Cb}$ & $\mathrm{Ib}$ & 37,21 evaluable & 84 & 62 & 14 & na \\
\hline \multirow[t]{2}{*}{ Colombo et $\mathrm{a}^{83}$} & PAT & III & 829 & 0 & 15.5 & na & 3.7 \\
\hline & PLD & & & & 7.9 & & 3.7 \\
\hline De Geest et $\mathrm{al}^{84}$ & IXA & ॥ & 5I, 49 evaluable & 0 & 14.3 & 40.8 & na \\
\hline Kavanagh et al ${ }^{85}$ & $\mathrm{Cn}$ & ॥ & 36,34 evaluable & 0 & 15 & 35 & na \\
\hline \multirow[t]{2}{*}{ Rose et $\mathrm{al}^{86}$} & $C n+C b$ & III & 247 & 0 & 32 & na & 3.5 \\
\hline & PLD & & & & 11 & & 3.5 \\
\hline \multirow[t]{2}{*}{ Vergote et al ${ }^{87}$} & $\mathrm{Cn}$ & III & 461 & 0 & 4 & na & 2.3 \\
\hline & PLD or TOP & & & & 11 & & 4.4 \\
\hline Kavanagh et a ${ }^{88}$ & $C n+P L D$ & ॥ & 39 & 0 & 27.8 & 51.3 & 6 \\
\hline \multirow[t]{2}{*}{ Vergote et $\mathrm{a}^{89}$} & $C n+P L D$ & III & 125 & 0 & na & na & 5.6 \\
\hline & PLD & & & & & & 3.7 \\
\hline Matulonis et $\mathrm{a}^{90}$ & $\mathrm{Cb}+\mathrm{PEM}$ & II & 45,44 evaluable & 100 & 51.1 & 31.1 & 7.57 \\
\hline Miller et a ${ }^{91}$ & PEM high dose & ॥ & 5I, 48 evaluable & 0 & 21 & 35 & 2.9 \\
\hline \multirow[t]{2}{*}{ Vergote et $\mathrm{al}^{92}$} & PEM standard & ॥ & I02, 91 evaluable & 0 & 9.3 & 32.6 & 2.8 \\
\hline & PEM high dose & & & & 10.4 & 29.2 & 2.8 \\
\hline Sehouli et al ${ }^{93}$ & $\mathrm{Cb}+\mathrm{PEM}$ & ॥ & 66,61 evaluable & 100 & 32.8 & 31.8 & 9.4 \\
\hline Teneriello et a $\left.\right|^{94}$ & $\mathrm{nP}$ & II & 46,44 evaluable & 100 & 64 & na & 8.5 \\
\hline Coleman et $\mathrm{al}^{95}$ & $\mathrm{nP}$ & ॥ & $5 I, 47$ evaluable & 0 & 23 & 36 & 4.5 \\
\hline Tsubamoto et al ${ }^{96}$ & $\mathrm{Iri}+\mathrm{Cb}$ & II & 40 & na & $\begin{array}{l}\text { Sensitive: } 52 \text {; } \\
\text { resistant: } 21\end{array}$ & na & $\begin{array}{l}\text { Sensitive: 3.7; } \\
\text { resistant: 9.I }\end{array}$ \\
\hline Pecorelli et $\mathrm{al}^{97}$ & Gim & ॥ & 69 & 27.5 & 24.6 & 31.9 & na \\
\hline
\end{tabular}

Abbreviations: $\mathrm{Cb}$, carboplatin; Cn, canfosfamide; EOC, epithelial ovarian cancer; Gim, gimatecan; Iri, irinotecan; IXA, ixabepilone; na, not available; nP, nab-paclitaxel; PLD, pegylated liposomal doxorubicin; PAT, patupilone; TOP, topotecan; PEM, pemetrexed; TR, trabectedin; mPFS, median progression-free survival.

The marker CD105 is actually used to measure MVD because it is expressed almost exclusively on endothelial cells in solid tumors undergoing neoangiogenesis, and it modulates angiogenesis by regulating cellular proliferation, differentiation, and migration. ${ }^{16}$ Two studies investigated CD105/MVD in EOC and found it to be an independent predictor of poor survival. ${ }^{17,18}$

\section{Proangiogenic and antiangiogenic factors in EOC}

Regulation of angiogenesis occurs through a dynamic balance of proangiogenic and antiangiogenic factors that maintain physiological homeostasis; in fact, in normal tissue, the vasculature remains quiescent. In neoplastic tissues, upregulation of proangiogenic factors (eg, VEGF, fibroblast growth factor [FGF], and platelet-derived growth factor $[\mathrm{PDGF}]$ ), and downregulation of antiangiogenic factors (thrombospondin, angiostatin, and endostatin) tip the balance in favor of angiogenesis and neovascularization. ${ }^{19,20}$

Many environmental factors, including hypoxia and low $\mathrm{pH}$, hormones (progesterone, estrogen), growth factors (EGF, transforming growth factor $\beta$, FGF, PDGF, insulin-like growth factor 1) and cytokines (interleukin [IL]-1 and IL-6) stimulate VEGF expression. In addition to exogenous factors, many tumorigenic mutations lead to VEGF upregulation. These can include mutations in cellular oncogenes such as $s r c$, ras, and $b c r-a b l$ and in tumor suppressor genes such as p53, $p 73$, and $v H L{ }^{21}$

EOC overexpresses proangiogenic factors including VEGFs, FGF, angiopoietin, PDGFs, and proangiogenic cytokines such as tumor necrosis factor $\alpha$ and IL- 6 and IL-8. ${ }^{21}$ Of these, the members of the VEGF family are the most potent proangiogenic factors. VEGF is produced by cancer cells and is related to the invasive and metastatic potential. 22,23 
The VEGF axis consists of a family of structurally related proteins: VEGF-A, VEGF-B, VEGF-C, VEGF-D, VEGF-E, and placental growth factor, with VEGF-A being the major mediator of angiogenesis. ${ }^{24}$ These proteins interact with three VEGF tyrosine kinase receptors (VEGFR1-3) to initiate a cascade of downstream signaling pathways promoting endothelial cell migration, proliferation, and survival, leading to the formation of new blood vessels and the increase in permeability of existing blood vessels. VEGFR1 and VEGFR2 principally regulate angiogenesis, whereas VEGFR3 plays a lesser role in angiogenesis but is critical for lymphangiogenesis, and thus is implicated in the production of ascites and lymphatic dissemination of metastases. ${ }^{25,26}$

Various factors, such as Ins-P3, PI3-kinase, MAP (mitogen-activated protein) kinase, and JAK-STAT (Janus kinase-Signal Transducer and Activator of Transcription) have been implicated in VEGF signal transduction. ${ }^{27}$ Neuropilin 1 and neuropilin 2 are nontyrosine kinase coreceptors that enhance VEGF binding to its receptors and are thought to play an important role in angiogenesis. ${ }^{28}$ High levels of neuropilin 1 and neuropilin 2 have been observed in EOC. ${ }^{29}$ Notably, in EOC cells, VEGF expression was correlated with activation of STAT 3 and 5. Moreover, VEGFR1 and VEGFR2 expression was correlated with STAT3 and STAT5 expression, respectively. ${ }^{30}$ These findings suggest that VEGF/VEGFR autocrine loops may play a role in stimulating the growth and progression of EOC. Accordingly, one could speculate that blocking VEGF in EOC may produce direct antitumor effects in addition to antiangiogenic effects. ${ }^{31}$ Recently, it has been suggested that VEGF also exerts an immunosuppressive effect in cancer, as it was correlated with low levels of IL-12, inhibition of dendritic cell maturation, low numbers of natural killer T-cells, and upregulation of regulatory T cells. ${ }^{32-36}$ In addition, VEGF inhibits apoptosis of the newly formed hyperpermeable blood vessels. ${ }^{37}$

Significantly higher VEGF levels have been observed in patients with EOC in comparison with patients with benign ovarian pathology or borderline tumors. ${ }^{38-40}$ Even for patients with early-stage disease, cancers with elevated VEGF expression and preoperative high serum VEGF levels were associated with an increased risk of disease recurrence, and worse OS and disease-free survival. ${ }^{41,42}$

In patients with EOC, markedly elevated serum VEGF levels have been associated with advanced stage tumors, poorly differentiated tumors, increased incidence of metastases, occurrence of large volume ascites, and decreased survival. ${ }^{43}$

PDGF and its receptor are essential to pericyte recruitment, a critical component of maturing blood vessels, and have been detected in EOC and associated with higher-grade tumors and decreased survival. Endothelial cells express PDGFRs, and preclinical studies have shown that PDGFR activation leads to increased angiogenesis. PDGF secretion by tumor cells may also recruit stromal cells that further support angiogenesis through the release of VEGF. ${ }^{43}$

\section{Antiangiogenic therapies in EOC}

Blocking proangiogenic factors has been shown to be an effective strategy for controlling EOC tumor growth. ${ }^{20}$ There are two primary strategies to inhibit the VEGF pathway: inhibition of the VEGF ligand with antibodies or soluble receptors and inhibition of the VEGFR with tyrosine kinase inhibitors or receptor antibodies. Therapies that specifically target the VEGF ligand or its receptors, VEGFR-1 and VEGFR-2, inhibit only the VEGF pathway, and therefore inhibit angiogenesis without disrupting "off-target" pathways. In contrast, tyrosine kinase inhibitors that target the receptor have a wider range of inhibitor effects and may disrupt other secondary pathways that are mediated through receptor kinases.

To improve the therapeutic benefit and counteract compensatory escape mechanisms, another approach to antiangiogenic therapy is the simultaneous targeting of multiple angiogenic pathways at once, including the PDGF and FGF pathways. FGF and its receptors play an important role in the development of resistance to VEGF pathway inhibitors. ${ }^{20}$

In preclinical models, blocking VEGF, PDGF, and FGF pathways suppress tumor angiogenesis and MVD to a greater extent than selectively blocking the VEGF pathway. Several agents that target two or three pathways have been evaluated in Phase II trials in women with recurrent EOC. ${ }^{44}$ The main disadvantage is the potential for enhanced adverse effects. ${ }^{44}$

An alternative approach to thwarting angiogenesis is to disrupt the newly established vessels supplying the cancers by vascular disruptive agents (VDAs). These generally cause rapid blood vessel shutdown and subsequent tumor necrosis. ${ }^{45}$ Conventionally, the molecules known as VDAs are either derivatives of flavone acetic acid that are thought to act by invoking cytokine release such as tumor necrosis factor $\alpha$, or are tubulin-binding agents such as combretastatin. The selectivity of the tubulin-binding agents is thought in part to be a result of the rapid division of endothelial cells, but these agents also cause distortion of immature endothelial cells which lack a pericyte coating. This distortion induces thrombosis and vessel collapse. ${ }^{46}$ VDAs have minimal singleagent activity, as despite causing necrosis of the main cancer mass, a viable rim is left, which repopulates the cancer. It 
appears that VDAs eliminate cells that are less well vascularized (where the delivery of systemically administered chemotherapeutic drugs is limited), and cells that are resistant to radiotherapy, whereas cytotoxic drugs exert their greatest effects on cells in the viable rim of tumor tissue that survive the VDA treatment. Preclinical and some early clinical results suggest that greater efficacy can be obtained as combination therapy: VDAs with cytotoxic agents, active against the rapidly repopulating tumor rim, or with VEGF inhibitors that act by blocking repopulation with circulating endothelial progenitor cells. Unlike the chronic dosing schedule required to prevent angiogenesis, VDAs should be effective given as intermittent doses. Early single-group Phase II studies in patients have shown that the addition of VDAs such as vadimezan or fosbretabulin to standard chemotherapy is well tolerated and appears to produce a higher RR in the populations studied to date. ${ }^{47,48}$ Recruitment to two Phase II studies, ombrabulin/placebo with conventional carboplatin and paclitaxel chemotherapy and bevacizumab (BV) with or without fosbretabulin are underway in platinum-sensitive ovarian cancer in the United States (ClinicalTrials.gov identifier NCT01305213 and NCT01332656).

\section{Bevacizumab}

$\mathrm{BV}$ is a recombinant humanized monoclonal antibody of the immunoglobulin G1 isotype that binds to all isoforms of VEGF with high specificity and affinity, resulting in a potent VEGF-neutralizing activity. ${ }^{44,49}$ In the Gynecologic Oncology Group (GOG) 170D study, 62 patients who had received 1-2 prior regimens were treated with single-agent BV. The objective response rate was $21 \%$, with a median duration of response of 10.3 months. Twenty-five patients were progression free for 6 months (PF6 months) ${ }^{49}$

BV was also evaluated in combination with first-line chemotherapy; an RR of $62 \%-80 \%$ and favorable toxicity to chemotherapy alone were reported in three Phase II studies (Table 2)..$^{50-52}$ In addition, BV has been used in combination with intravenous/intraperitoneal chemotherapy. ${ }^{53}$ The feasibility of combining BV with carboplatin and dose-dense paclitaxel is currently being investigated in the OCTAVIA study. ${ }^{54} \mathrm{BV}$-related adverse events (AEs) (grade $\geq 3$ ) included thromboembolic effects, hypertension, and gastrointestinal perforation. ${ }^{54}$

In relapsed disease, $\mathrm{BV}$ has been combined with a nanoparticle albumin-bound formulation of paclitaxel (nabpaclitaxel) and oxaliplatin/gemcitabine. These studies showed that these combinations are feasible, with encouraging results in term of RRs and OS (Table 2). ${ }^{55,56}$ Given these promising efficacy results, BV has been incorporated into Phase III trials of first-line treatment for advanced-stage EOC (Table 2).

Two Phase III studies, the GOG218 and the International Collaborative Group for Ovarian Neoplasia (ICON) 7, examined the efficacy of BV in a first-line/adjuvant chemotherapy setting. ${ }^{57,58}$ The GOG218 trial was a three-group randomized

Table 2 Bevacizumab in the treatment of epithelial ovarian cancer

\begin{tabular}{|c|c|c|c|c|c|c|c|c|c|}
\hline Trial & Phase & Treatment & Patients & RR (\%) & $P$ & PFS (m) & $P$ & OS (m) & $P$ \\
\hline \multirow[t]{3}{*}{ GOG $218^{57}$} & III & $\mathrm{CP}$ & 625 & - & - & 10.3 & & 39.3 & \\
\hline & & CP-BV & 625 & - & - & 11.2 & 0.16 & 38.7 & 0.76 \\
\hline & & $\mathrm{CP}-\mathrm{BV} \rightarrow \mathrm{BV}$ & 625 & - & - & 14.1 & $<0.001$ & 39.7 & 0.45 \\
\hline \multirow[t]{2}{*}{$\operatorname{ICON} 7^{58}$} & III & CP-BV & 764 & 48 & $<0.001$ & 17.4 & 0.004 & NR & - \\
\hline & & $\mathrm{CP}-\mathrm{BV} \rightarrow \mathrm{BV}$ & 764 & 67 & & 19.8 & & NR & \\
\hline \multirow[t]{2}{*}{ OCEANS ${ }^{71}$} & III & CG & 242 & 57.4 & $<0.0001$ & 8.4 & $<0.00 \mathrm{I}$ & 35.2 & \\
\hline & & CG-BV & 242 & 78.5 & & 12.4 & & 33.3 & \\
\hline \multirow[t]{2}{*}{ AURELIA ${ }^{76}$} & III & Chemotherapy & 182 & 12.6 & 0.001 & 3.4 & $<0.0001$ & - & - \\
\hline & & chemotherapy-BV & 179 & 30.9 & & 6.7 & & - & - \\
\hline GOGI $70 d^{49}$ & II & BV & 62 & 21 & - & 4.7 & - & 17 & - \\
\hline \multirow[t]{2}{*}{ Garcia et a ${ }^{98}$} & ॥ & Methronomic & 70 & 24 & - & 7.2 & - & 16.9 & - \\
\hline & & cyclophosphamide-BV & & & & & & & \\
\hline Cannistra $^{62}$ & ॥ & BV & 44 & 15.9 & - & 4.4 & - & 10.7 & - \\
\hline Micha et a $\left.\right|^{50}$ & ॥ & CP-BV & 20 & 80 & - & - & - & - & - \\
\hline Penson et $\mathrm{a}^{51}$ & ॥ & $\mathrm{CP}-\mathrm{BV} \rightarrow \mathrm{BV}$ & 62 & 76 & - & $36(58 \%)$ & - & - & - \\
\hline Rose et al ${ }^{52}$ & ॥ & Oxaliplatin-docetaxel-BV & 95 & 62 & - & $12(70 \%)$ & - & - & - \\
\hline Konner et $\mathrm{a}^{53}$ & ॥ & Paclitaxel-BV ev-paclitaxel/CP ip & 41 & - & - & 28.6 & - & - & - \\
\hline Tillmanns et al ${ }^{55}$ & ॥ & Nab-paclitaxel-BV & 48 & 50 & - & 8.08 & - & 17.5 & - \\
\hline Horowitz et a ${ }^{56}$ & II & Oxaliplatin-gemcitabine-BV & 19 & - & - & 9.2 & - & 28 & - \\
\hline OCTAVIA ${ }^{54}$ & ॥ & $\mathrm{CP}-\mathrm{BV} \rightarrow \mathrm{BV}$ & 189 & - & - & - & - & - & - \\
\hline
\end{tabular}

Abbreviations: BV, bevacizumab; CG, carboplatin-gemcitabine; CP, carboplatin-paclitaxel; NR, not yet reached; PFS, progression-free survival; m, month; OS, overall survival; RR, response rate. 
study that evaluated 1873 patients with macroscopic residual stage 3 or any stage 4 ovarian, fallopian tube, and peritoneal cancer (Table 2). Each of all the three study regimens included 22 cycles lasting 3 weeks each, with intravenous infusions on day 1, and with the first 6 cycles consisting of standard chemotherapy (carboplatin-paclitaxel). ${ }^{57}$

The patients were randomly assigned to receive one of the following: control group, a combination of standard chemotherapy ( 6 cycles) with placebo in cycles 2 through 6 , followed by placebo alone, for a total of 22 cycles; BVinitiation treatment group, standard chemotherapy (6 cycles) in combination with BV $(15 \mathrm{mg} / \mathrm{kg})$ in cycles 2 through 6 , followed by placebo alone for a total of 22 cycles; and BV-throughout treatment group, standard chemotherapy (6 cycles) with BV added in cycles 2 through 6, followed by the continuation of BV alone, for a total of 22 cycles. ${ }^{57}$ At a median of 17.4 months of follow-up compared with the control group, the hazard of progression or death was lower in the BV-initiation group (hazard ratio [HR], 0.908; $P=0.16)$ and significantly lower in the BV-throughout group (HR, 0.717; $P<0.001$ ). In an analysis of PFS, in which data for patients with increased CA-125 levels were censored, the median PFS was 12.0 months in the control group but 18.0 months in the BV-throughout group (HR, 0.645; $P<0.001)$. However, no significant difference in OS was reported. ${ }^{57}$

Results of updated analyses of PFS and OS, performed after $47 \%$ of the patients had died, were consistent with those from the original analyses. However, the potential to detect a difference in survival is likely to be limited by lack of control for multiple subsequent regimens, including crossover to $\mathrm{BV}$ or other anti-VEGF agents. ${ }^{57}$ Hypertension of grade 2 or greater was significantly $(P<0.001)$ more common with BV than placebo. ${ }^{57}$

The ICON7 trial had a similar design and enrolled 1528 patients with newly diagnosed high-risk stage $1 / 2 \mathrm{~A}$ and stage 3/4 ovarian, fallopian tube, and peritoneal cancer who were randomly assigned to six cycles of chemotherapy alone or six cycles of chemotherapy plus BV $(7.5 \mathrm{mg} / \mathrm{kg})$, followed by 12 cycles of maintenance BV (Table 2). ${ }^{54}$ The rate of complete or partial remission was $48 \%$ in the standard-therapy group and $67 \%$ in the BV group $(P<0.001) .{ }^{58}$ The median PFS, with a median follow-up of 19.4 months, was 17.3 months in the standard-therapy group and 19.0 months in the BV group (HR, 0.81; $P=0.004) .{ }^{58}$ After a median follow-up of 28 months, results were very similar to those of the primary analysis $(P=0.001)$, and a long-term improvement in PFS was observed with BV (HR, 0.87; $P=0.04) .{ }^{58}$
Among the 465 women at high risk for progression, 386 had disease progression, and survival was greater with BV than with standard therapy (HR, $0.73 ; P=0.002) .{ }^{58}$ The updated PFS curves were similar to those obtained in the primary analysis after 24 months of follow-up. After a median follow-up of 28 months, the survival data did not demonstrate a significant improvement in OS (HR, $0.85 ; P=0.11)$. A post hoc exploratory OS analysis showed a significant improvement in the high-risk-for-progression subgroup (HR, 0.64; $P=0.002)$. Hypertension of grade 2 or higher was observed more often in the BV group. Final survival data are expected in $2013 .^{58}$

In the GOG218 trial, Burger et $\mathrm{al}^{57}$ declared that the potential to see differences in OS was limited by postprogression therapies, including crossover to the experimental agent BV. In addition, Korn et $\mathrm{al}^{59}$ observed in his letter that postprogression therapies will attenuate differences in OS but that the observed attenuated differences are the correct measure of clinical benefit for the patients, provided that standard-of-care postprogression therapies are used in both treatment groups. ${ }^{55}$ Although in the ICON7 trial ${ }^{58}$ less than $4 \%$ of the patients in the control group received postprogression antiangiogenic treatments, among the GOG218 results, these data are not yet available.

Burger argues that the analysis of this group has not yet been made, but in a subanalysis of ICON7 in which the results of patients with high-risk disease were evaluated, as in the GOG218, a substantial advantage in the use of BV on OS was found. ${ }^{60}$ If this benefit is to be confirmed, the OS discrepancy could be a result of the activity of the postprogression therapy and would support the idea of PFS as an end-point definitive to verify the influence of new agents on EOC. ${ }^{60}$

In their letter, Copur et $\mathrm{al}^{61}$ disagree with the authors' conclusion that BV could be considered a front-line treatment option, as several previously reported randomized trials of paclitaxel as consolidation and maintenance therapy have shown significant improvements in PFS with a comparable toxicity, in the occurrence of AEs, and in quality-of-life profile. ${ }^{61-66}$ In addition, treatment with paclitaxel is more cost-effective than treatment with BV, which also has a lack of biologic markers predictive of efficacy. ${ }^{66}$ The introduction of taxanes as consolidation therapy must be weighed against the risk of neuropathy. To reinforce the performance and decrease the adverse effects, an appropriate schedule should be considered. ${ }^{61}$ Finally, the implementation of extended taxane and antiangiogenic therapy may not be mutually exclusive, and indeed it would be intriguing to study the potential benefit of standard chemotherapy in combination with BV 
followed by either continued paclitaxel combined with BV or BV alone in patients who would have been eligible for enrollment in GOG218. ${ }^{61}$

According to Mountzios and Pentheroudakis, ${ }^{67}$ the most intriguing finding in the study by Perren et $\mathrm{al}^{58}$ was the greater benefit from BV in patients at high risk for disease progression than that seen among patients at lower risk, supporting the notion that normalization of tumor vasculature confers maximal benefit in patients with advanced disease. ${ }^{67} \mathrm{~A}$ possible explanation for these results is that BV loses its efficacy in synergistic action with cytotoxic chemotherapy in case of the absence of macroscopic residual disease, as was the case of the AVANT study in colorectal cancer. ${ }^{68,69}$ In both studies, PFS curves converged a few months after BV discontinuation, suggesting that antiangiogenic treatment may delay, but not prevent, disease progression. ${ }^{63}$ About this similarity between colon cancer and EOC, Perren et $\mathrm{al}^{58}$ observed that in both diseases, the presence of a larger mass may lead to a better effect of BV because of a larger tumor vasculature. ${ }^{67}$ Moreover, Goel et $\mathrm{al}^{70}$ proposed that the normalization of tumor vasculature is responsible for reduction in hypoxia and interstitial-fluid pressure. The idea of an intermittent schedule is intriguing, but at the moment there are insufficient clinical data to support this, because in the intermittent dosing, the evaluation of hypoxia and interstitial-fluid pressure have to be carefully assessed. ${ }^{67}$

Several other Phase III trials of BV for the treatment of recurrent EOC have been conducted.

The Ovarian Cancer Education Awareness Network (OCEANS) trial ${ }^{71}$ evaluated the efficacy of BV in combination with gemcitabine-carboplatin (GC) in patients with recurrent, platinum-sensitive EOC, primary peritoneal, or fallopian tube cancers (Table 2). At the median follow-up of 24 months, the addition of BV to GC led to a statistically significant increase in PFS and in overall RR compared with GC with placebo (HR, 0.484; $P<0.0001$ and $P<0.0001$, respectively). ${ }^{71}$ With regard to $\mathrm{OS}$, at the time of the final PFS analysis, the data were immature. ${ }^{71}$

The authors reported a higher incidence of serious AEs in the BV group, consisting of grade 3 or greater hypertension, proteinuria, and reversible posterior leukoencephalopathy syndrome, whereas gastrointestinal perforation occurred in only two patients after study discontinuation. ${ }^{71}$

In the trial by Herzog et al, ${ }^{72}$ the authors investigated the concordance between overall response and PFS determined by CA-125 and Response Evaluation Criteria In Solid Tumors (RECIST) criteria, the effect of early CA-125 changes over subsequent overall response by RECIST criteria, and the prognostic value of CA-125 response and CA-125 PFS to predict radiologic response and PFS by RECIST criteria. ${ }^{72}$ The PFS, as an indicator of favorable ultimate treatment success, has shown an $86 \%-87 \%$ concordance rate between CA-125 and RECIST response in both groups. ${ }^{72}$ Among RECIST responders, an early CA-125 decrease of $25 \%$ was observed in a high number of patients, and CA-125 progression preceded RECIST progression in $35 \%$ of patients. ${ }^{72}$ The GCI proposed new criteria for the evaluation of progression during therapy and recurrence after treatment on the basis of either the objective RECIST criteria or the serum CA-125 evaluation. ${ }^{73}$ The GCI $^{73}$ also stressed the importance of collection of data such as CA-125 alone, CA-125 and symptoms, and RECIST alone to better modulate protocols in those patients demonstrating measurable stable disease but CA-125 increase. In a recent GOG Phase II trial, the GCIG CA-125 criteria would have generated the same conclusion as RECIST for response and 6 months PFS. However, approximately $10 \%$ of patients might demonstrate progression earlier by CA-125. ${ }^{74}$

Aghajanian et $\mathrm{al}^{71}$ did not use the marker as a predictor of response to treatment and did not include data related to biomarker modifications. The advantage of PFS as a primary end point is that it reflects tumor shrinkage and disease control with the treatment used in the study. However, because the trial was designed so that patients would receive BV or placebo until progression or unacceptable toxicity, the lack of biomarker analysis and the use of RECIST parameters alone as eligibility criteria and as a measure of the response to drugs could cause needless prolonging of the treatment, with excessive costs and little gain in PFS. ${ }^{75}$

A randomized Phase III trial, A Study of Avastin (Bevacizumab) Added to Chemotherapy in Patients With Platinum-resistant Ovarian Cancer (AURELIA), ${ }^{76}$ enrolled 361 patients to compare chemotherapy versus chemotherapy plus BV (Table 2). Median PFS was significantly prolonged with chemotherapy plus BV versus chemotherapy alone (HR, 0.48; $P<0.001$ ). ${ }^{76}$ Similarly, chemotherapy plus BV was associated with a significant increase in overall $R R$ $(P=0.001) .{ }^{76}$ The most common grade 3 or higher AEs with $\mathrm{BV}$, described as being of special interest, were hypertension, thromboembolic events, proteinuria, and gastrointestinal perforation. Of note, strict eligibility criteria, which excluded patients with more than two previous anticancer treatments, a history of bowel obstruction/abdominal fistula, or clinical evidence of rectosigmoid involvement, may have minimized BV-associated AEs in this study. A final analysis will be reported in $2013 .{ }^{76}$ 


\section{Conclusion}

High-grade serous EOC is characterized by the overexpression of VEGF, which has been recognized as a central promoter of the activation phase of angiogenesis.

VEGF expression and indices of angiogenesis in primary tumors have been correlated directly with the extent of disease, and inversely with PFS or OS. Direct targeting of this pathway can be achieved by sequestration of the VEGF protein, using monoclonal antibodies or engineered bindingsite molecules. The most widely studied agent has been BV in Phase II and III trials with concurrent chemotherapy and maintenance. Two Phase III trials in patients newly diagnosed with EOC have reported a modest improvement in PFS, but less effect on OS. ${ }^{57,58}$

The combined effect of cytoreductive surgery and chemotherapy would tend to minimize tumor-associated VEGF production, as well as the size of any residual disease, which is quite different from the management of large-volume metastatic disease in other settings. Taken together, these effects could theoretically reduce the effect of BV during primary chemotherapy and might favor using $\mathrm{BV}$ in the setting of recurrent disease, as illustrated by data from the OCEANS trial in platinum-sensitive recurrent disease. ${ }^{71}$

Expected toxicities from BV were observed (including thromboembolic events and hypertension). Most of the serious events tended to occur during primary chemotherapy and within the perioperative period, with fewer dose-limiting events noted during maintenance therapy.

Although the Phase III trials met their primary endpoints for improvement in PFS, the magnitude of benefit was not as great as anticipated based on Phase II data in patients with recurrent disease. Because of the design of the trials, it is not possible to state how much of the improvement in PFS is related to the total duration of therapy, the integration with concurrent chemotherapy, or the maintenance after chemotherapy. However, maximal benefit was achieved in the population that received BV during and after chemotherapy. In addition, both trials demonstrated a trend for greater benefit in patients with more extensive disease, based on either the results from cytoreductive surgery (ICON7) or through exclusion of patients with small-volume disease and CA-125 progression (GOG0218). . $7,58^{-51}$

The magnitude of this effect appears greater in ICON7 compared with GOG0218, and it is possible that a higher proportion of patients in the GOG trial were able to obtain commercial BV (or other related agents) after completion of protocol-directed therapy.
However, according to the many experimental studies, there is strong evidence for introducing BV in the medical treatment of patients with advanced and recurrent EOC. $\mathrm{BV}$ in association with carboplatin and paclitaxel, followed by maintenance treatment with $\mathrm{BV}$, could be considered an attractive and active treatment for patients with advanced EOC, but other angiogenesis inhibitors are under careful evaluation for introduction to clinical practice. Nevertheless, further investigations and large clinical trials are needed to understand the safety and effectiveness of the new agents in this setting, the optimal duration and timing of treatment, and the activity in association with other targeted drugs and chemotherapeutic agents. Certainly, and more importantly, it is necessary to identify biologic factors predictive of efficacy to choose the most appropriate antiangiogenic agent in the integrated treatment of EOC.

Other critical issues remain unresolved, such as the correct identification of women most likely to benefit from antiangiogenic agents, the elucidation of resistance to VEGF blockade and the development of alternative antiangiogenic strategies, and the development of targeted tumor-specific antiangiogenic therapies to avoid AEs associated with the inhibition of normal physiologic angiogenesis. Mature data are awaited from ongoing studies evaluating multitargeted inhibitors of receptor-associated tyrosine kinases in the setting of primary and maintenance therapy.

\section{Disclosure}

The authors report no conflicts of interest in this work.

\section{References}

1. Siegel R, Ward E, Brawley O, Jemal A. Cancer statistics, 2011: the impact of eliminating socioeconomic and racial disparities on premature cancer deaths. CA Cancer J Clin. 2011;61(4):212-236.

2. Fleming GF, Ronnet BM, Seidman J, Zaino RJ, Rubin SC. Epithelial ovarian cancer. In: Barakat RR, Markman M, Randall ME, editors. Principles and Practice of Gynecologic Oncology, 5th ed. Philadelphia: Lippincot Williams and Wilkins; 2009:763-836.

3. Kusumbe AP, Bapat SA. Ovarian stem cell biology and the emergence of ovarian cancer stem cells. In: Bapat S, editor. Cancer Stem Cells: Identification and Targets. New York: John Wiley and Sons; 2008: 95-110.

4. Ozols RF. Update on the management of ovarian cancer. Cancer J. 2002;8 Suppl 1:S22-S30.

5. Markman M, Reichman B, Hakes T, et al. Responses to second-line cisplatin-based intraperitoneal therapy in ovarian cancer: influence of a prior response to intravenous cisplatin. J Clin Oncol. 1991;9(10): 1801-1805.

6. Pisano C, Bruni GS, Facchini G, Marchetti C, Pignata S. Treatment of recurrent epithelial ovarian cancer. Ther Clin Risk Manag. 2009;5(4): 421-426.

7. Folkman J. Tumor angiogenesis: therapeutic implications. NEngl J Med. 1971;285(21):1182-1186.

8. Folkman J. What is the evidence that tumors are angiogenesis dependent? J Natl Cancer Inst. 1990;82(1):4-6. 
9. Ferrara N, Kerbel RS. Angiogenesis as a therapeutic target. Nature. 2005;438(7070):967-974.

10. Jain RK. Normalization of tumor vasculature: an emerging concept in antiangiogenic therapy. Science. 2005;307(5706):58-62.

11. Jain RK. Normalizing tumor vasculature with anti-angiogenic therapy: a new paradigm for combination therapy. Nat Med. 2001;7(9): 987-989.

12. Weidner N. Intratumor microvessel density as a prognostic factor in cancer. Am J Pathol. 1995;147(1):9-19.

13. Stone PJ, Goodheart MJ, Rose SL, et al. The influence of microvessel density on ovarian carcinogenesis. Gynecol Oncol. 2003;90(3): 566-571.

14. Palmer JE, Sant Cassia LJ, Irwin CJ, Morris AG, Rollason TP. Prognostic value of measurements of angiogenesis in serous carcinoma of the ovary. Int J Gynecol Pathol. 2007;26(4):395-403.

15. Gadducci A, Ferrero A, Cosio S, et al. Intratumoral microvessel density in advanced epithelial ovarian cancer and its use as a prognostic variable. Anticancer Res. 2006;26(5B):3925-3932.

16. Taskiran C, Erdem O, Onan A, et al. The prognostic value of endoglin (CD105) expression in ovarian carcinoma. Int $J$ Gynecol Cancer. 2006;16(5):1789-1793.

17. Rubatt JM, Darcy KM, Hutson A, et al. Independent prognostic relevance of microvessel density in advanced epithelial ovarian cancer and associations between CD31, CD105, p53 status, and angiogenic marker expression: a Gynecologic Oncology Group study. Gynecol Oncol. 2009;112(3):469-474.

18. Henriksen R, Gobl A, Wilander E, et al. Expression and prognostic significance of TGF-beta isotypes, latent TGF-beta 1 binding protein, TGF-beta type I and type II receptors, and endoglin in normal ovary and ovarian neoplasms. Lab Invest. 1995;73(2):213-220.

19. Hicklin DJ, Ellis LM. Role of the vascular endothelial growth factor pathway in tumor growth and angiogenesis. J Clin Oncol. 2005;23(5): 1011-1027.

20. Burger RA. Overview of anti-angiogenic agents in development for ovarian cancer. Gynecol Oncol. 2011;121(1):230-238.

21. Martin L, Schilder R. Novel approaches in advancing the treatment of epithelial ovarian cancer: the role of angiogenesis inhibition. J Clin Oncol. 2007;25(20):2894-2901.

22. Barnett B, Kryczek I, Cheng P, Zou W, Curiel TJ. Regulatory T cells in ovarian cancer: biology and therapeutic potential. Am J Reprod Immunol. 2005;54(6):369-377.

23. Kim R, Emi M, Tanabe K. Cancer immunosuppression and autoimmune disease: beyond immunosuppressive networks for tumour immunity. Immunology. 2006;119(2):254-264.

24. Ferrara N. VEGF and the quest for tumour angiogenesis factors. Nat Rev Cancer. 2002;2(10):795-803.

25. Ellis LM, Hicklin DJ. VEGF-targeted therapy: mechanisms of antitumour activity. Nat Rev Cancer. 2008;8(8):579-591.

26. Ramakrishnan S, Subramanian IV, Yokoyama Y, Geller M. Angiogenesis in normal and neoplastic ovaries. Angiogenesis. 2005;8(2):169-182.

27. Chen H, Ye D, Xie X, Chen B, Lu W. VEGF, VEGFRs expressions and activated STATs in ovarian epithelial carcinoma. Gynecol Oncol. 2004;94(3):630-635.

28. Soker S, Takashima S, Miao HQ, Neufeld G, Klagsbrun M. Neuropilin-1 is expressed by endothelial and tumor cells as an isoform-specific receptor for vascular endothelial growth factor. Cell. 1998;92(6): $735-745$.

29. Osada R, Horiuchi A, Kikuchi N, et al. Expression of semaphorins, vascular endothelial growth factor, and their common receptor neuropilins and alleic loss of semaphorin locus in epithelial ovarian neoplasms: increased ratio of vascular endothelial growth factor to semaphorin is a poor prognostic factor in ovarian carcinomas. Hum Pathol. 2006;37(11):1414-1425.

30. Korn EL, Freidlin B, Abrams JS. Overall survival as the outcome for randomized clinical trials with effective subsequent therapies. $J$ Clin Oncol. 2011;29(17):2439-2442.

31. Kumaran GC, Jayson GC, Clamp AR. Antiangiogenic drugs in ovarian cancer. Br J Cancer. 2009;100(1):1-7.
32. Bellati F, Napoletano C, Gasparri ML, et al. Current knowledge and open issues regarding bevacizumab in gynaecological neoplasms. Crit Rev Oncol Hematol. 2012;83(1):35-46.

33. Papamichail M, Perez SA, Gritzapis AD, Baxevanis CN. Natural killer lymphocytes: biology, development, and function. Cancer Immunol Immunother. 2004;53(3):176-186.

34. Dikov MM, Ohm JE, Ray N, et al. Differential roles of vascular endothelial growth factor receptors 1 and 2 in dendritic cell differentiation. J Immunol. 2005;174(1):215-222.

35. Lissoni P, Malugani F, Bonfanti A, et al. Abnormally enhanced blood concentrations of vascular endothelial growth factor (VEGF) in metastatic cancer patients and their relation to circulating dendritic cells, IL-12 and endothelin-1. J Biol Regul Homeost Agents. 2001;15(2): 140-144.

36. Alon T, Hemo I, Itin A, Pe'er J, Stone J, Keshet E. Vascular endothelial growth factor acts as a survival factor for newly formed retinal vessels and has implications for retinopathy of prematurity. Nat Med. 1995;1(10):1024-1028.

37. Kassim SK, El-Salahy EM, Fayed ST, et al. Vascular endothelial growth factor and interleukin- 8 are associated with poor prognosis in epithelial ovarian cancer patients. Clin Biochem. 2004;37(5): 363-369.

38. Cooper BC, Ritchie JM, Broghammer CL, et al. Preoperative serum vascular endothelial growth factor levels: significance in ovarian cancer. Clin Cancer Res. 2002;8(10):3193-3197.

39. Boss EA, Massuger LF, Thomas CM, et al. Vascular endothelial growth factor in ovarian cyst fluid. Cancer. 2001;91(2):371-377.

40. Paley PJ, Staskus KA, Gebhard K, et al. Vascular endothelial growth factor expression in early stage ovarian carcinoma. Cancer. 1997;80(1): 98-106.

41. Hefler LA, Zeillinger R, Grimm C, et al. Preoperative serum vascular endothelial growth factor as a prognostic parameter in ovarian cancer. Gynecol Oncol. 2006;103(2):512-517.

42. Li L, Wang L, Zhang W, et al. Correlation of serum VEGF levels with clinical stage, therapy efficacy, tumor metastasis and patient survival in ovarian cancer. Anticancer Res. 2004;24(3b):1973-1199.

43. Rusnati M, Presta M. Fibroblast growth factors/fibroblast growth factor receptors as targets for the development of anti-angiogenesis strategies. Curr Pharm Des. 2007;13(20):2025-2044.

44. Ferrara N, Gerber HP, LeCouter J. The biology of VEGF and its receptors. Nat Med. 2003;9(6):669-676.

45. Hinnen P, Eskens FA. Vascular disrupting agents in clinical development. Br J Cancer. 2007;96(8):1159-1165.

46. Horsman MR, Siemann DW. Pathophysiologic effects of vasculartargeting agents and the implications for combination with conventional therapies. Cancer Res. 2006;66(24):11520-11539.

47. McKeage MJ. Clinical trials of vascular disrupting agents in advanced non-small-cell lung cancer. Clin Lung Cancer. 2011;12(3): 143-147.

48. Zweifel M, Jayson GC, Reed NS, et al. Phase II trial of combretastatin A4 phosphate, carboplatin, and paclitaxel in patients with platinumresistant ovarian cancer. Ann Oncol. 2011;22(9):2036-2041.

49. Burger RA, Sill MW, Monk BJ, Greer BE, Sorosky JI. Phase II trial of bevacizumab in persistent or recurrent epithelial ovarian cancer or primary peritoneal cancer: a Gynecologic Oncology Group Study. J Clin Oncol. 2007;25(33):5165-5171.

50. Micha JP, Goldstein BH, Rettenmaier MA, et al. A phase II study of outpatient first-line paclitaxel, carboplatin, and bevacizumab for advanced-stage epithelial ovarian, peritoneal, and fallopian tube cancer. Int J Gynecol Cancer. 2007;17(4):771-776.

51. Penson RT, Dizon DS, Cannistra SA, et al. Phase II study of carboplatin, paclitaxel, and bevacizumab with maintenance bevacizumab as first-line chemotherapy for advanced mullerian tumors. J Clin Oncol. 2010;28(1):154-159.

52. Rose PG, Drake R, Braly PS et al. Preliminary results of a phase II study of oxaliplatin, docetaxel, and bevacizumab as first-line therapy of advanced cancer of the ovary, peritoneum, and fallopian tube. J Clin Oncol. 2009;27. Abstract 5546. 
53. Konner JA, Grabon DM, Gerst SR, et al. Phase II study of intraperitoneal paclitaxel plus cisplatin and intravenous paclitaxel plus bevacizumab as adjuvant treatment of optimal stage II/III epithelial ovarian cancer. J Clin Oncol. 2011;29(35):4662-4668.

54. Gonzalez-Martin A, Gladieff L, Tholander B et al. Safety of frontline bevacizumab (BEV) combined with weekly paclitaxel (wPAC) and q3w carboplatin (C) for ovarian cancer (OC): results from OCTAVIA. J Clin Oncol. 2012;30(Suppl). Abstract 5017.

55. Tillmanns TD, Lowe MP, Schwartzberg LS et al. A phase II study of bevacizumab with nab-paclitaxel in patients with recurrent, platinum resistant primary epithelial ovarian or primary peritoneal carcinoma. J Clin Oncol. 2010;28(Suppl). Abstract 5009.

56. Horowitz NS, Penson RT, Duda DG, et al. Safety, efficacy, and biomarker exploration in a phase II study of bevacizumab, oxaliplatin, and gemcitabine in recurrent Müllerian carcinoma. Clin Ovarian Cancer Other Gynecol Malig. 2011;4(1):26-33.

57. Burger RA, Brady MF, Bookman MA, et al; Gynecologic Oncology Group. Incorporation of bevacizumab in the primary treatment of ovarian cancer. N Engl J Med. 2011;365(26):2473-2483.

58. Perren TJ, Swart AM, Pfisterer J, et al; ICON7 Investigators. A phase 3 trial of bevacizumab in ovarian cancer. $N$ Engl J Med. 2011;365(26): 2484-2496.

59. Korn EL, Freidlin B, Abrams JS. Bevacizumab in ovarian cancer. N Engl J Med. 2012;366(13):1256.

60. Burger RA. Bevacizumab in ovarian cancer. N Engl J Med. 2012; 366(13):1256-1257.

61. Copur MS, Obermiller AM, Ramaekers R. Bevacizumab in ovarian cancer. N Engl J Med. 2012 29;366(13):1256-1257.

62. Cannistra SA. Evaluating new regimens in recurrent ovarian cancer: how much evidence is good enough? J Clin Oncol. 2010;28(19): 3101-3103.

63. Markman M, Liu PY, Moon J, et al. Impact on survival of 12 versus 3 monthly cycles of paclitaxel $(175 \mathrm{mg} / \mathrm{m} 2)$ administered to patients with advanced ovarian cancer who attained a complete response to primary platinum-paclitaxel: follow-up of a Southwest Oncology Group and Gynecologic Oncology Group phase 3 trial. Gynecol Oncol. 2009;114(2):195-198

64. Micha JP, Goldstein BH, Graham C, et al. Improved survival with single-agent paclitaxel consolidation/maintenance therapy in advanced ovarian carcinoma. Oncology. 2006;71(1-2):49-53.

65. Micha JP, Goldstein BH, Mattison JA, et al. Experience with singleagent paclitaxel consolidation following primary chemotherapy with carboplatin, paclitaxel, and gemcitabine in advanced ovarian cancer. Gynecol Oncol. 2005;96(1):132-135.

66. Lesnock JL, Farris C, Krivak TC, Smith KJ, Markman M. Consolidation paclitaxel is more cost-effective than bevacizumab following upfront treatment of advanced epithelial ovarian cancer. Gynecol Oncol. 2011;122(3):473-478.

67. Mountzios G, Pentheroudakis G. Bevacizumab in ovarian cancer. N Engl J Med. 2012;366(13):1257.

68. Gerber HP, Ferrara N. Pharmacology and pharmacodynamics of bevacizumab as monotherapy or in combination with cytotoxic therapy in preclinical studies. Cancer Res. 2005;65(3):671-680.

69. de Gramont A, Van Cutsem E, Schmoll HJ, et al. Bevacizumab plus oxaliplatin-based chemotherapy as adjuvant treatment for colon cancer (AVANT): a phase 3 randomised controlled trial. Lancet Oncol. 2012;13(12):1225-1233.

70. Goel S, Duda DG, Xu L, et al. Normalization of the vasculature for treatment of cancer and other diseases. Physiol Rev. 2011;91(3): 1071-1121.

71. Aghajanian C, Blank SV, Goff BA, et al. OCEANS: a randomized, double-blind, placebo-controlled phase III trial of chemotherapy with or without bevacizumab in patients with platinum-sensitive recurrent epithelial ovarian, primary peritoneal, or fallopian tube cancer. J Clin Oncol. 2012;30(17):2039-2045.

72. Herzog TJ, Vermorken JB, Pujade-Lauraine et al. Correlation between CA-125 serum level and response by RECIST in a phase III recurrent ovarian cancer study. Gynecol Oncol. 2011;122(2):350-355.
73. Rustin GJ, Vergote I, Eisenhauer E, et al; Gynecological Cancer Intergroup. Definitions for response and progression in ovarian cancer clinical trials incorporating RECIST 1.1 and CA 125 agreed by the Gynecological Cancer Intergroup (GCIG). Int J Gynecol Cancer. 2011;21(2): 419-423.

74. Randall LM, Sill MW, Burger RA, et al. Predictive value of serum CA-125 levels in patients with persistent or recurrent epithelial ovarian cancer or peritoneal cancer treated with bevacizumab on a Gynecologic Oncology Group phase II trial. Gynecol Oncol. 2012;124(3): 563-856.

75. Tomao F, Tomao S, Panici PB. Improvement in progression-free survival in OCEANS bevacizumab arm: a critical point of view. $J$ Clin Oncol. 2013;31(1):166-167.

76. Pujade-Lauraine E, Hilpert F, Weber B et al. AURELIA: a randomized phase III trial evaluating bevacizumab (BEV) plus chemotherapy (CT) for platinum (PT)-resistant recurrent ovarian cancer (OC). J Clin Oncol. 2012;30. Abstract LBA5002.

77. Sessa C, De Braud F, Perotti A, et al. Trabectedin for women with ovarian carcinoma after treatment with platinum and taxanes fails. J Clin Oncol. 2005;23(9):1867-1874.

78. Krasner CN, McMeekin DS, Chan S, et al. A Phase II study of trabectedin single agent in patients with recurrent ovarian cancer previously treated with platinum-based regimens. Br J Cancer. 2007;97(12): 1618-1624.

79. Del Campo J, Roszak A, Ciuleanu T et al. Phase II open label randomized study of trabectedin given as two different dosing schedules in women with platinum-sensitive, recurrent ovarian carcinoma: preliminary results. In: proceedings of the American Society of Clinical Oncology 2006 (42nd Annual Meeting of the American Society of Clinical Oncology); June 2-6, 2006, Atlanta). Abstract 5031.

80. Monk BJ, Herzog TJ, Kaye SB, et al. Trabectedin plus pegylated liposomal Doxorubicin in recurrent ovarian cancer. $J$ Clin Oncol. 2010;28(19):3107-3114.

81. Smit WM, Šufliarsky J, Werner TL, et al. A phase II study of patupilone (EPO906) in patients with platinum-resistant or platinum-refractory ovarian cancer. Clin Ovarian Other Gynecol Cancer. In press 2012.

82. Forster M, Kaye S, Oza A, et al. A phase Ib and pharmacokinetic trial of patupilone combined with carboplatin in patients with advanced cancer. Clin Cancer Res. 2007;13(14):4178-4184.

83. Colombo N, Kutarska E, Dimopoulos M, et al. Randomized, openlabel, phase III study comparing patupilone (EPO906) with pegylated liposomal doxorubicin in platinum-refractory or -resistant patients with recurrent epithelial ovarian, primary fallopian tube, or primary peritoneal cancer. J Clin Oncol. 2012;30(31):3841-3847.

84. De Geest K, Blessing JA, Morris RT, et al. Phase II clinical trial of ixabepilone in patients with recurrent or persistent platinum- and taxaneresistant ovarian or primary peritoneal cancer: a gynecologic oncology group study. J Clin Oncol. 2010 1;28(1):149-153.

85. Kavanagh JJ, Gershenson DM, Choi H, et al. Multi-institutional phase 2 study of TLK286 (TELCYTA, a glutathione S-transferase P1-1 activated glutathione analog prodrug) in patients with platinum and paclitaxel refractory or resistant ovarian cancer. Int J Gynecol Cancer. 2005;15(4):593-600.

86. Rose P, Edwards R, Finkler N, et al. Phase 3 study: canfosfamide (C, TLK286) plus carboplatin (P) vs liposomal doxorubicin (D) as 2nd-line therapy of platinum (P)-resistant ovarian cancer (OC). J Clin Oncol. 2007;25. Abstract LBA5529.

87. Vergote I, Finkler N, del Campo J, et al. Single agent, canfosfamide (C, TLK286) vs pegylated liposomal doxorubicin (D) or topotecan (T) in 3rdline treatment of platinum (P)-refractory or resistant ovarian cancer $(\mathrm{OC})$ : phase 3 study results. J Clin Oncol. 2007;25. Abstract LBA5528.

88. Kavanagh JJ, Levenback CF, Ramirez PT, et al. Phase 2 study of canfosfamide in combination with pegylated liposomal doxorubicin in platinum and paclitaxel refractory or resistant epithelial ovarian cancer. J Hematol Oncol. 2010;3:9.

89. Vergote I, Finkler NJ, Hall JB, et al. Randomized phase III study of canfosfamide in combination with pegylated liposomal doxorubicin compared with pegylated liposomal doxorubicin alone in platinumresistant ovarian cancer. Int J Gynecol Cancer. 2010;20(5):772-780. 
90. Matulonis UA, Horowitz NS, Campos SM, et al. Phase II study of carboplatin and pemetrexed for the treatment of platinumsensitive recurrent ovarian cancer. J Clin Oncol. 2008;26(35): 5761-5766.

91. Miller DS, Blessing JA, Krasner CN, et al. Phase II evaluation of pemetrexed in the treatment of recurrent or persistent platinum-resistant ovarian or primary peritoneal carcinoma: a study of the Gynecologic Oncology Group. J Clin Oncol. 2009;27(16):2686-2691.

92. Vergote I, Calvert H, Kania M, et al. A randomised, double-blind, phase II study of two doses of pemetrexed in the treatment of platinumresistant, epithelial ovarian or primary peritoneal cancer. Eur J Cancer. 2009;45(8):1415-1423.

93. Sehouli J, Alvarez AM, Manouchehrpour S, et al. A phase II trial of pemetrexed in combination with carboplatin in patients with recurrent ovarian or primary peritoneal cancer. Gynecol Oncol. 2012;124(2): 205-209.

94. Teneriello MG, Tseng PC, Crozier M, et al. Phase II evaluation of nanoparticle albumin-bound paclitaxel in platinum-sensitive patients with recurrent ovarian, peritoneal, or fallopian tube cancer. J Clin Oncol. 2009;27(9):1426-1431.
95. Coleman RL, Brady WE, McMeekin DS, et al. A phase II evaluation of nanoparticle, albumin-bound (nab) paclitaxel in the treatment of recurrent or persistent platinum-resistant ovarian, fallopian tube, or primary peritoneal cancer: a Gynecologic Oncology Group study. Gynecol Oncol. 2011;122(1):111-115.

96. Tsubamoto H, Kawaguchi R, Ito K, et al. Phase II study of carboplatin and weekly irinotecan combination chemotherapy in recurrent ovarian cancer: a Kansai clinical oncology group study (KCOG0330). Anticancer Res. 2013;33(3):1073-1079.

97. Pecorelli S, Ray-Coquard I, Tredan O, et al. Phase II of oral gimatecan in patients with recurrent epithelial ovarian, fallopian tube or peritoneal cancer, previously treated with platinum and taxanes. Ann Oncol. 2010;21(4):759-765.

98. Garcia AA, Hirte H, Fleming G, et al. Phase II clinical trial of bevacizumab and low-dose metronomic oral cyclophosphamide in recurrent ovarian cancer: a trial of the California, Chicago, and Princess Margaret Hospital phase II consortia. J Clin Oncol. 2008;26(1):76-82

\section{Publish your work in this journal}

OncoTargets and Therapy is an international, peer-reviewed, open access journal focusing on the pathological basis of all cancers, potential targets for therapy and treatment protocols employed to improve the management of cancer patients. The journal also focuses on the impact of management programs and new therapeutic agents and protocols on

\section{Dovepress}

patient perspectives such as quality of life, adherence and satisfaction The manuscript management system is completely online and includes a very quick and fair peer-review system, which is all easy to use. Visit http://www.dovepress.com/testimonials.php to read real quotes from published authors. 